\title{
COMPUTATIONAL STUDIES OF WATER ADSORPTION IN ZEOLITES
}

S. A. Zygmunt

Department of Physics and Astronomy

Valparaiso University

Valparaiso, IN 46383

L. A. Curtiss and L. E. Iton

Argonne National Laboratory

Argonne, Mlinois 60439

May, 1995
RECEIVED

JAN 301995

OSTI

To be submitted to the

Proceedings of the International Zeolite Symposium

October 10-20, 1995, Quebec, Canada

The submitted manuscript has been authored by a contractor of the U. S. Government under contract No. W-31-109-ENG-38. Accordingly, the U. S. Government retains a nonexclusive, royalty-free license to publish or reproduce the published form of this contribution, or allow others to do so, for U. S. Government purposes.

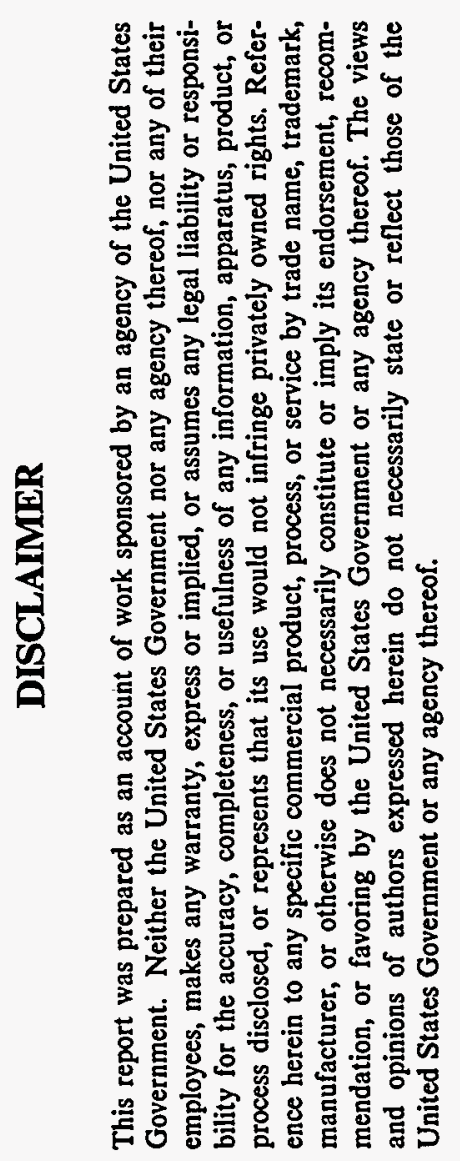

*Work supported by the U.S. Department of Energy, Office of Basic Energy Sciences, Division of Materials Sciences, under Contract No. W-31-109-ENG-38 and the Petroleum Research Fund of the American Chemical Society. 
$\therefore$

-

$$
\begin{aligned}
& \cdots+\cdots \\
& \cdots
\end{aligned}
$$




\title{
Computational studies of water adsorption in zeolites
}

\author{
S. A. Zygmunta, L. A. Curtiss ${ }^{b}$, and L. E. Iton ${ }^{b}$ \\ aDepartment of Physics and Astronomy, Valparaiso University, \\ Valparaiso, IN 46383 (email: szygmunt@exodus.valpo.edu)
}

\author{
bArgonne National Laboratory, Argonne, IL 60439 (email: \\ curtiss@cmt.anl.gov)
}

We have performed high-level ab initio calculations using Hartree-Fock (HF) theory, Møller-Plesset perturbation theory (MP2), and density-functional theory (DFT) to study the geometry and energetics of the adsorption complex involving $\mathrm{H}_{2} \mathrm{O}$ and the Brønsted acid site in the zeolite H-ZSM-5. These calculations use aluminosilicate cluster models for the zeolite framework with as many as $28 \mathrm{~T}$ atoms ( $\mathrm{T}=\mathrm{Si}, \mathrm{Al}$ ). - We included geometry optimization in the local vicinity of the acid site at the MP2 and DFT levels of theory for the smallest cluster, while in the larger clusters this was done at the HF/6-31G(d) level of theory. We have also calculated corrections for zero-point energies, extensions to higher basis sets, and higher levels of electron correlation. Results for the adsorption energy and geometry of this complex are reported and compared with previous theoretical and experimental values.

\section{INTRODUCTION}

Brønsted acid chemistry is a dominant feature of the catalysis by zeolites in many important industrial applications. A reliable theoretical treatment of the proton affinity of H-ZSM-5 zeolite has been obtained in previous work using high-level $a b$ initio calculations on large cluster models [1]. Proton transfer to a strong adsorbed base has also been studied theoretically in the interaction of ammonia with the Brønsted acid site [2-4]. The interaction of weak bases, e.g., $\mathrm{H}_{2} \mathrm{O}$, presents a more equivocal situation. What kind of equilibrium structure is. formed when $\mathrm{H}_{2} \mathrm{O}$ is adsorbed at the Brønsted acid site in H-ZSM-5? Some experimental evidence, most notably in the form of IR spectroscopy, has suggested that the acidic proton is transferred to $\mathrm{H}_{2} \mathrm{O}$ and that an ion-pair structure is most stable [5,6]. One ab initio theoretical study [7] also gave evidence to support this conclusion. However, recent ab initio calculations have disputed this claim and have led to a reinterpretation of the IR spectra in a manner consistent with a neutral hydrogen-bonded adsorbate $[8,9]$. These studies have suggested that the ion-pair complex should be regarded as a transition state and not a true equilibrium geometry. However, almost all of these theoretical studies have used small clusters to represent the acid site, and none have accounted for electron correlation in their optimization of molecular geometries, so they are open to criticism on the basis of these limitations. 
provided a test of the accuracy of MP2 theory and BLYP when compared to the more computationally demanding QCISD(T) method.

\section{RESULTS AND DISCUSSION}

The reaction energies of $\mathrm{H}_{2} \mathrm{O}$ interacting at the hydroxyl site of aluminosilicate clusters of $3,8,18$, and $28 \mathrm{~T}$ atoms representing H-ZSM-5 are listed in Tables 1 and 2. The quantities calculated in this study include $\Delta \mathrm{E}_{\mathrm{ion}}, \Delta \mathrm{E}_{\mathrm{cov}}$, $\Delta \mathrm{E}_{\mathrm{rel}}$, and $\Delta \mathrm{E}_{\text {desorp. The }} \Delta \mathrm{E}_{\mathrm{ion}}$ is the complexation energy of the ionic complex

$\Delta \mathrm{E}_{\text {ion }}=\mathrm{E}\left(\mathrm{Z}^{-}\right)+\mathrm{E}\left(\mathrm{H}_{3} \mathrm{O}^{+}\right)-\mathrm{E}\left(\mathrm{Z}^{-} \ldots \mathrm{OH}_{3}{ }^{+}\right)$

where $\mathrm{Z}^{-}$is the unprotonated zeolitic cluster, and $\mathrm{Z}^{-} \ldots \mathrm{OH}_{3}+$ is the ion-pair complex.

Table 1

$\mathrm{H}_{2} \mathrm{O}$ reaction energies, $\Delta \mathrm{E}_{\mathrm{cov}}$ and $\Delta \mathrm{E}_{\mathrm{ion}}$ (in $\mathrm{kcal} / \mathrm{mol}$ ), for different cluster sizes ${ }^{\mathrm{a}}$

\begin{tabular}{|c|c|c|c|c|c|c|c|c|}
\hline \multirow[b]{2}{*}{ Method/Basis } & \multicolumn{4}{|c|}{$\Delta \mathrm{E}_{\mathrm{COV}}$} & \multicolumn{4}{|c|}{$\Delta \mathrm{E}_{\mathrm{ion}}$} \\
\hline & 3 & 8 & 18 & 28 & 3 & 8 & 18 & 28 \\
\hline $\mathrm{HF} / 3-21 \mathrm{G}$ & - & 31.7 & 34.8 & 34.2 & - & 154.6 & 154.2 & 154.6 \\
\hline$H F / 6-31 G(d)$ & 15.2 & 14.7 & 17.0 & 16.7 & 138.4 & 131.1 & 130.9 & 129.7 \\
\hline $\mathrm{MP} 2 / 6-31 \mathrm{G}(\mathrm{d})^{\mathrm{b}}$ & 22.1 & 20.2 & - & - & 150.1 & 138.1 & $=$ & - \\
\hline
\end{tabular}

${ }^{a}$ All results are from the constant volume relaxation procedure as described in text, except for cluster 3 , which is a full geometry optimization. Cluster 3 is illustrated in Figure 1. Zero-point energies not included in values.

${ }^{b}$ At $H F / 6-31 G(d)$ geometry for cluster 8 .

Table 2

$\mathrm{H}_{2} \mathrm{O}$ reaction energies, $\Delta \mathrm{E}_{\mathrm{rel}}$ and $\Delta \mathrm{E}_{\text {desorp }}$ (in $\mathrm{kcal} / \mathrm{mol}$ ), for different cluster sizes $^{\mathrm{a}}$

\begin{tabular}{|c|c|c|c|c|c|c|c|c|}
\hline \multirow[b]{2}{*}{ Method/Basis } & \multicolumn{4}{|c|}{$\Delta \mathrm{E}_{\mathrm{rel}}$} & \multicolumn{4}{|c|}{$\Delta \mathrm{E}_{\text {desorp }}$} \\
\hline & 3 & 8 & 18 & 28 & 3 & 8 & 18 & 28 \\
\hline $\mathrm{HF} / 3-21 \mathrm{G}$ & - & -14.1 & -13.0 & -10.4 & - & 31.7 & 34.8 & 34.2 \\
\hline $\mathrm{HF} / 6-31 \mathrm{G}(\mathrm{d})$ & -14.5 & -16.9 & -14.7 & -13.3 & 15.2 & 14.7 & 17.0 & 16.7 \\
\hline$M P 2 / 6-31 G(d)^{b}$ & -6.2 & -12.4 & - & - & 22.1 & 20.2 & - & - \\
\hline
\end{tabular}

aAl results are from the constant volume relaxation procedure as described in text, except for cluster 3, which is a full geometry optimization. Cluster 3 is illustrated in Figure 1. Zero-point energies not included in values.

${ }^{b}$ At HF/6-31G(d) geometry for cluster 8 . 
The calculations presented here extend our earlier study of the adsorption of $\mathrm{H}_{2} \mathrm{O}$ on a $2 \mathrm{~T}$ atom cluster model of H-ZSM-5 [10]. They incorporate local geometry optimization, large cluster size, and electron correlation in a unified way. We have obtained results for the geometry and adsorption energy of the neutral $\mathrm{H}_{2} \mathrm{O}$ adsorption complex in $\mathrm{H}-\mathrm{ZSM}-5$, and have found that it is more stable than the ion-pair structure. The calculated adsorption energy is roughly consistent with the published experimental value.

\section{THEORETICAL METHODS}

The theoretical calculations presented here are based on ab initio molecular orbital theory [11,12] and density-functional theory [13]. We used four aluminosilicate clusters of increasing size to model the Brønsted acid site in $\mathrm{H}$ ZSM-5. These clusters include $3,8,18$, and $28 \mathrm{~T}$ atoms, and have a total number of 14, 34, 69, and 101 atoms, respectively. Each cluster includes one Al atom and a charge-balancing proton to maintain a neutral zeolite framework, and is terminated by $\mathrm{H}$ atoms at the periphery. Their stoichiometries are $\mathrm{H}_{9} \mathrm{Si}_{2} \mathrm{AlO}_{2}$, $\mathrm{H}_{19} \mathrm{Si}_{7} \mathrm{AlO}_{7}, \mathrm{H}_{29} \mathrm{Si}_{17} \mathrm{AlO}_{22}$, and $\mathrm{H}_{33} \mathrm{Si}_{27} \mathrm{AlO}_{40}$, respectively. For the $3 \mathrm{~T}$ atom cluster, the adsorption complex was found by using full geometry optimization. This allowed us to calculate zero-point vibrational energy corrections directly. These corrections were then used as estimates for the complexes between $\mathrm{H}_{2} \mathrm{O}$ and the larger cluster models. For the $8 \mathrm{~T}$ atom cluster, the constant-volume relaxation (CVR) method [1] was used. Atoms at the periphery of the cluster were fixed at positions determined from X-ray diffraction studies of H-ZSM-5 [14], while the central $\mathrm{O}_{3} \mathrm{SiOHAlO} \mathrm{O}_{3}$ atoms near the acid site were fully relaxed. In addition, the six intermolecular degrees of freedom between the framework and the adsorbate molecule were fully optimized. The $\mathrm{H}_{2} \mathrm{O}$ and $\mathrm{H}_{3} \mathrm{O}^{+}$geometries were held fixed at the optimized geometries of the isolated molecules. This constrained relaxation scheme is a useful model for the effect of an adsorbate on the local structure of the acid site.

After CVR optimization, the effect of more distant atoms was then included by embedding this $8 \mathrm{~T}$ atom cluster in successively larger fragments of crystalline H-ZSM-5 to obtain first the $18 \mathrm{~T}$ atom and then the $28 \mathrm{~T}$ atom cluster. This procedure yielded a cluster size energy correction term. Our procedure is open to the criticism that the intermolecular degrees of freedom were not re-optimized in the 18 and $28 \mathrm{~T}$ atom clusters, but we tested its accuracy by re-optimizing the intermolecular coordinates of the $18 \mathrm{~T}$ atom complex with $\mathrm{H}_{3} \mathrm{O}^{+}$at the HF/3-21G level and comparing them to those obtained in the $8 \mathrm{~T}$ atom cluster. Changes in bond lengths and angles on the order of $3-5 \%$ were noted, but the total energy. after re-optimization decreased by less than $1 \mathrm{kcal} / \mathrm{mol}$, so we believe that this procedure is justified.

Both $3-21 \mathrm{G}$ and $6-31 \mathrm{G}(\mathrm{d})$ basis sets were used in the calculations involving the 8,18 , and $28 \mathrm{~T}$ atom clusters, while in the $3 \mathrm{~T}$ atom cluster an additional calculation was performed with the $6-311+G(3 d f, 2 p)$ basis set. This result for the smallest cluster model allowed us to find a basis set energy correction, which was then used as an estimate for the larger clusters based on G2(MP2) theory [15]. In the $3 \mathrm{~T}$ atom cluster, the effect of electron correlation was treated by MP2 theory, the non-local BLYP formulation of DFT [16], and quadratic configuration interaction (QCISD(T)) [17]. These results allowed us to find correlation energy corrections which were used as estimates for the larger clusters. They also 
provided a test of the accuracy of MP2 theory and BLYP when compared to the more computationally demanding QCISD(T) method.

\section{RESULTS AND DISCUSSION}

The reaction energies of $\mathrm{H}_{2} \mathrm{O}$ interacting at the hydroxyl site of aluminosilicate clusters of $3,8,18$, and $28 \mathrm{~T}$ atoms representing H-ZSM-5 are listed in Tables 1 and 2 . The quantities calculated in this study include $\Delta \mathrm{E}_{\mathrm{ion}}, \Delta \mathrm{E}_{\mathrm{cov}}$, $\Delta E_{\text {rel }}$, and $\Delta E_{\text {desorp. The }} \Delta \mathrm{E}_{\mathrm{ion}}$ is the complexation energy of the ionic complex

$\Delta \mathrm{E}_{\text {ion }}=\mathrm{E}\left(\mathrm{Z}^{-}\right)+\mathrm{E}\left(\mathrm{H}_{3} \mathrm{O}^{+}\right)-\mathrm{E}\left(\mathrm{Z}^{-} \ldots \mathrm{OH}_{3}{ }^{+}\right)$

where $\mathrm{Z}^{-}$is the unprotonated zeolitic cluster, and $\mathrm{Z}^{-} \ldots \mathrm{OH}_{3}+$ is the ion-pair complex.

Table 1

$\mathrm{H}_{2} \mathrm{O}$ reaction energies, $\Delta \mathrm{E}_{\mathrm{cov}}$ and $\Delta \mathrm{E}_{\mathrm{ion}}$ (in $\mathrm{kcal} / \mathrm{mol}$ ), for different cluster sizes ${ }^{\mathrm{a}}$

\begin{tabular}{|c|c|c|c|c|c|c|c|c|}
\hline \multirow[b]{2}{*}{ Method/Basis } & \multicolumn{4}{|c|}{$\Delta \mathrm{E}_{\mathrm{cov}}$} & \multicolumn{4}{|c|}{$\Delta \mathrm{E}_{\mathrm{ion}}$} \\
\hline & 3 & 8 & 18 & 28 & 3 & 8 & 18 & 28 \\
\hline $\mathrm{HF} / 3-21 \mathrm{G}$ & - & 31.7 & 34.8 & 34.2 & - & 154.6 & 154.2 & 154.6 \\
\hline $\mathrm{HF} / 6-31 \mathrm{G}(\mathrm{d})$ & 15.2 & 14.7 & 17.0 & 16.7 & 138.4 & 131.1 & 130.9 & 129.7 \\
\hline $\mathrm{MP} 2 / 6-31 \mathrm{G}(\mathrm{d})^{\mathrm{b}}$ & 22.1 & 20.2 & - & - & 150.1 & 138.1 & - & - \\
\hline
\end{tabular}

${ }^{\text {aAll }}$ results are from the constant volume relaxation procedure as described in text, except for cluster 3, which is a full geometry optimization. Cluster 3 is illustrated in Figure 1. Zero-point energies not included in values.

${ }^{b}$ At HF/6-31G(d) geometry for cluster 8 .

Table 2

$\mathrm{H}_{2} \mathrm{O}$ reaction energies, $\Delta \mathrm{E}_{\mathrm{rel}}$ and $\Delta \mathrm{E}_{\text {desorp }}$ (in $\mathrm{kcal} / \mathrm{mol}$ ), for different cluster sizes $^{a}$

\begin{tabular}{|c|c|c|c|c|c|c|c|c|}
\hline \multirow[b]{2}{*}{ Method/Basis } & \multicolumn{4}{|c|}{$\Delta \mathrm{E}_{\mathrm{rel}}$} & \multicolumn{4}{|c|}{$\Delta \mathrm{E}_{\text {desorp }}$} \\
\hline & 3 & 8 & 18 & 28 & 3 & 8 & 18 & 28 \\
\hline$H F / 3-21 G$ & - & -14.1 & -13.0 & -10.4 & - & 31.7 & 34.8 & 34.2 \\
\hline $\mathrm{HF} / 6-31 \mathrm{G}(\mathrm{d})$ & -14.5 & -16.9 & -14.7 & -13.3 & 15.2 & 14.7 & 17.0 & 16.7 \\
\hline MP2/6-31G(d)b & -6.2 & -12.4 & - & - & 22.1 & 20.2 & - & - \\
\hline
\end{tabular}

${ }^{a}$ All results are from the constant volume relaxation procedure as described in text, except for cluster 3 , which is a full geometry optimization. Cluster 3 is illustrated in Figure 1. Zero-point energies not included in values.

${ }^{b}$ At HF/6-31G(d) geometry for cluster 8 . 
The $\Delta \mathrm{E}_{\mathrm{cov}}$ is the complexation energy of the covalent (hydrogen-bonded) complex

$\Delta \mathrm{E}_{\mathrm{cov}}=\mathrm{E}(\mathrm{ZH})+\mathrm{E}\left(\mathrm{H}_{2} \mathrm{O}\right)-\mathrm{E}\left(\mathrm{ZH} . . . \mathrm{OH}_{2}\right)$

where $\mathrm{ZH}$ is the protonated zeolitic cluster and $\mathrm{ZH}$.... $\mathrm{OH}_{2}$ is the covalent complex. The $\Delta \mathrm{E}_{\mathrm{rel}}$ is the energy difference between the covalent and ionic complexes

$\Delta \mathrm{E}_{\mathrm{rel}}=\mathrm{E}\left(\mathrm{ZH} . . . \mathrm{OH}_{2}\right)-\mathrm{E}\left(\mathrm{Z}^{-} \ldots \mathrm{OH}_{3}{ }^{+}\right)$

where a positive value indicates that the ionic complex is more stable. The $\Delta E_{\text {desorp }}$ is the energy required to remove the $\mathrm{H}_{2} \mathrm{O}$ molecule from the most stable complex (ionic or covalent):

$\Delta \mathrm{E}_{\text {desorp }}=\mathrm{E}(\mathrm{ZH})+\mathrm{E}\left(\mathrm{H}_{2} \mathrm{O}\right)-\min \left[\mathrm{E}\left(\mathrm{Z}^{-} . . . \mathrm{H}_{3} \mathrm{O}^{+}\right), \mathrm{E}\left(\mathrm{ZH} . . . \mathrm{OH}_{2}\right)\right]$

The results in Tables 1 and 2 for these energies are based on calculations which include relaxation of the local region of the cluster near the hydroxyl site as described in the previous section. Results for the $3 \mathrm{~T}$ atom cluster, for which full optimizations were carried out, are also included in the table. The structures of the ion-pair and hydrogen-bonded configurations for the $3 \mathrm{~T}$ cluster are illustrated in Figure 1. A comparison of the calculated geometrical parameters at HF, MP2, and BLYP levels of theory using the $6-31 \mathrm{G}(\mathrm{d})$ basis set is shown in Table 3. At all these levels, the ion-pair structure is a transition state, while the covalent structure is a local minimum in the potential energy surface. In Table 3 note particularly the significant influence of electron correlation on the hydrogen-bond distances $\mathrm{OH}_{1}$ and $\mathrm{OH}_{2}$ in the covalent complex. Complexation energies for both structures are also strongly influenced by correlation. Also note that MP2 and BLYP give very similar results for the covalent structure.

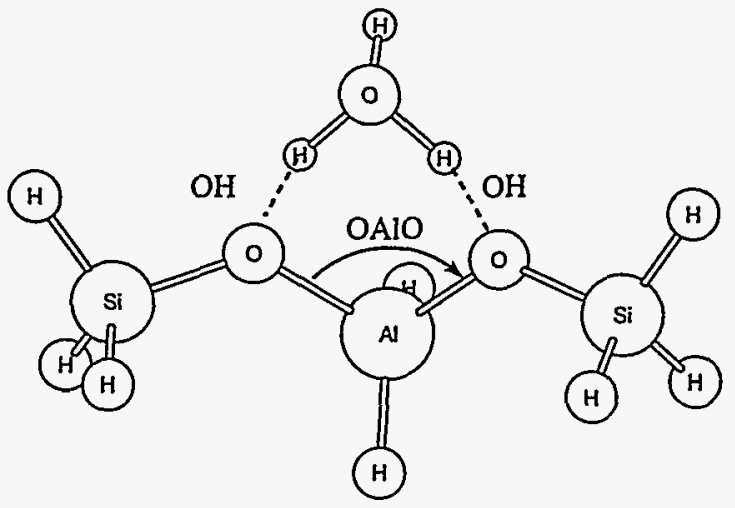

(a)

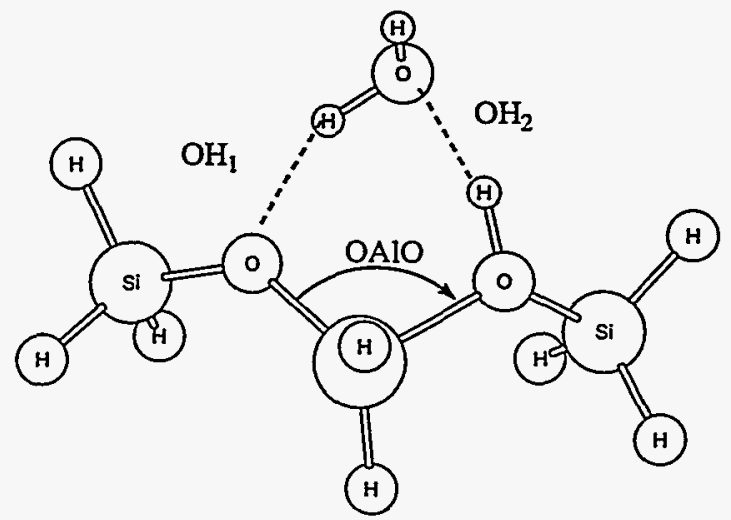

(b)

Figure 1. Optimized structures of (a) ion-pair and (b) hydrogen-bonded (covalent) configurations for $\mathrm{H}_{2} \mathrm{O}$ interacting with the hydroxyl site in an aluminosilicate cluster with three $\mathrm{T}$ atoms. 
Table 3

Structure and Energetics of $3 \mathrm{~T}$ Atom Clusters at Various Levels of Theory (see Figure 1 for explanation of coordinates) ${ }^{a}$

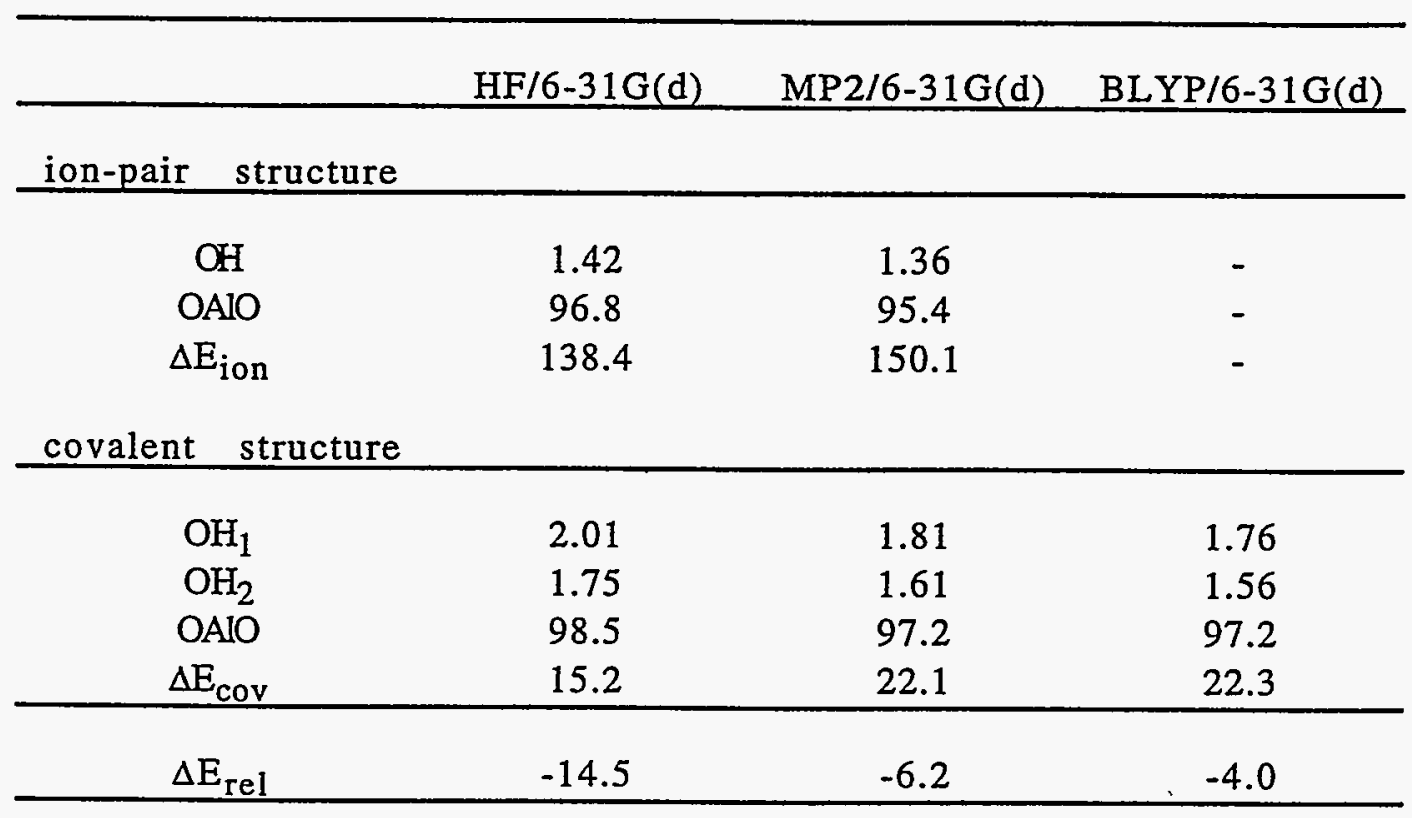

aBond lengths in $\AA$, angles in degrees, and energies in $\mathrm{kcal} / \mathrm{mol}$.

The HF/6-31G(d) calculations for the $8 \mathrm{~T}$ atom cluster also show that the lowest energy structure is a hydrogen-bonded adsorption complex between $\mathrm{H}_{2} \mathrm{O}$ and the zeolite framework, in which the adsorbate is anchored to the framework by $O . . . \mathrm{H}$ linkages of 1.70 and $2.06 \AA$. These bond lengths are within $0.05 \AA$ of the HF results for the $3 \mathrm{~T}$ atom cluster shown in Table 3 , and they are nearly the same as those found in a previous study [18] using a slightly different DZP basis set and a smaller $3 \mathrm{~T}$ atom zeolite cluster. The adsorbed complexes $\mathrm{ZH} . . . \mathrm{OH}_{2}$ and $\mathrm{Z}^{-} \ldots \mathrm{OH}_{3}{ }^{+}$are shown in Figure 2 for the 8,18 , and $28 \mathrm{~T}$ atom clusters. The terminating $\mathrm{H}$ atoms at the periphery of these clusters are not shown in the figure.

Table 4 shows our energy corrections to the calculated desorption energy of $14.7 \mathrm{kcal} / \mathrm{mol}$ in the $8 \mathrm{~T}$ atom cluster. Extending the cluster size to $28 \mathrm{~T}$ atoms $[\Delta(C S)]$ increased the binding energy by $2.0 \mathrm{kcal} / \mathrm{mol}$, and treating electron correlation in the $3 \mathrm{~T}$ atom cluster by MP2 theory $[\Delta(\mathrm{MP} 2)]$ gave an additional increase of $6.9 \mathrm{kcal} / \mathrm{mol}$. Correlation effects beyond the MP2 level using the 6$31 \mathrm{G}(\mathrm{d})$ basis $[\Delta(\mathrm{QCI})]$ decreased the desorption energy by $0.9 \mathrm{kcal} / \mathrm{mol}$ in the $3 \mathrm{~T}$ cluster. The zero-point energy correction $[\Delta(\mathrm{ZPE})]$ from the $3 \mathrm{~T}$ cluster gave a 2.9 $\mathrm{kcal} / \mathrm{mol}$ decrease in desorption energy, and the correction from G2(MP2) theory for extension to a higher-level $6-311+G(3 d f, 2 p)$ basis set $[\Delta(B S)]$ gave an additional $5.5 \mathrm{kcal} / \mathrm{mol}$ decrease. This gives a best estimate of $14.3 \mathrm{kcal} / \mathrm{mol}$ for the desorption energy of $\mathrm{H}_{2} \mathrm{O}$ in $\mathrm{H}-\mathrm{ZSM}-5$ at $0 \mathrm{~K}$. Thermal effects will cause this value to decrease, but it is unclear if the usual ideal gas corrections used in theoretical enthalpy calculations [19] are valid in the restricted environment of the zeolite interior. 


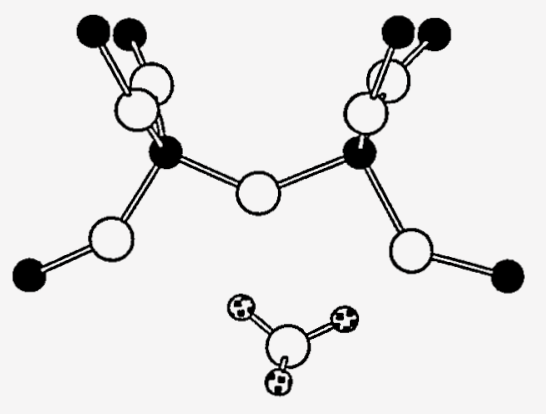

(a)

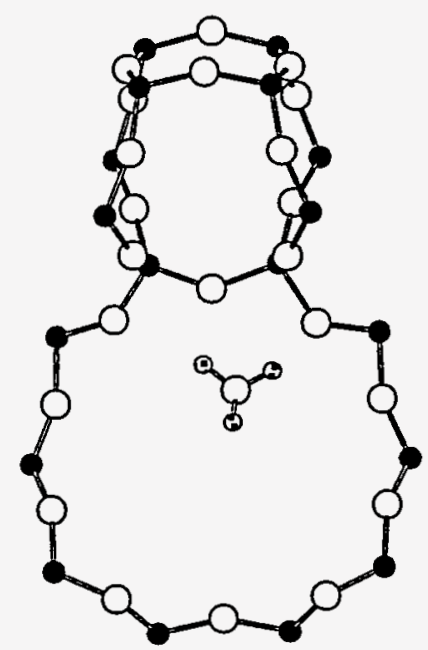

(c)

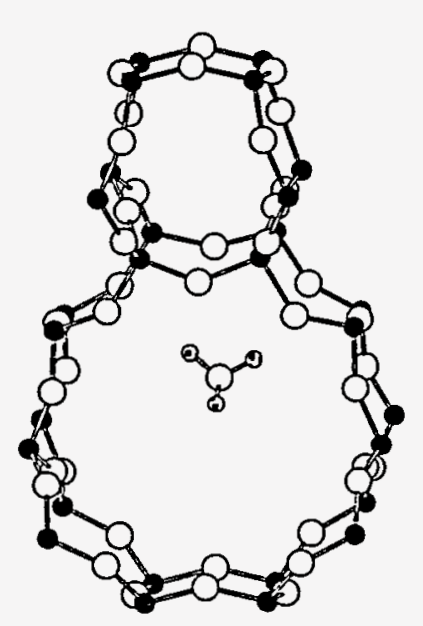

(e)

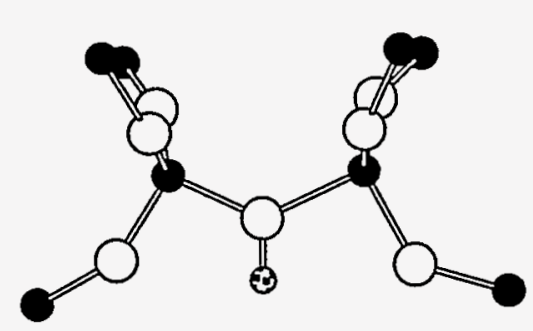

$g=0$

(b)

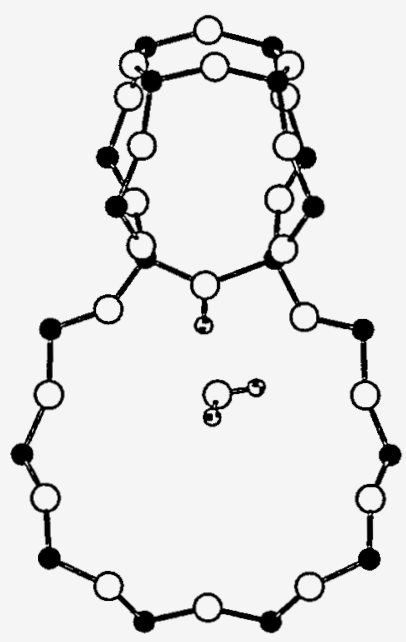

(d)

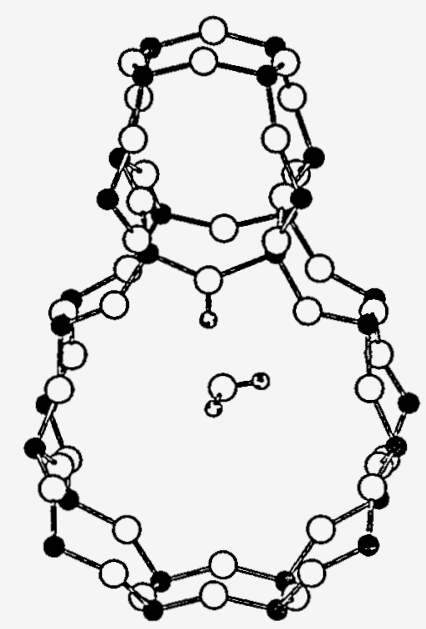

(f)

Figure 2. $\mathrm{Z}^{-} \ldots \mathrm{OH}_{3}{ }^{+}$and $\mathrm{ZH} . . . \mathrm{OH}_{2}$ complexes for cluster size $8(\mathrm{a}, \mathrm{b})$, $18(\mathrm{c}, \mathrm{d})$, and $28(\mathrm{e}, \mathrm{f})$. Terminating $\mathrm{H}$ atoms not shown. 
A previous theoretical estimate [20] for the desorption energy in a $2 \mathrm{~T}$ atom cluster was $11.2 \mathrm{kcal} / \mathrm{mol}$, but this approach included no correction terms besides $\Delta(\mathrm{MP} 2)$ and only allowed for a single $\mathrm{O}$...H linkage between the $\mathrm{ZH}$ framework and the $\mathrm{H}_{2} \mathrm{O}$ molecule. Our earlier study [10], using a similar cluster model but including $\Delta(\mathrm{MP} 2), \Delta(\mathrm{QCI})$, and $\Delta(\mathrm{BS})$ corrections, gave a value of $10.8 \mathrm{kcal} / \mathrm{mol}$. Other theoretical work using a $3 \mathrm{~T}$ atom cluster [7] resulted in a value of 14.8 $\mathrm{kcal} / \mathrm{mol}$, but it did not account for the $\Delta(\mathrm{CS}), \Delta(\mathrm{QCI})$, and $\Delta(\mathrm{BS})$ terms calculated here. By comparison, the experimental enthalpy of adsorption, which was obtained from a Clausius-Clapeyron analysis of $\mathrm{p}(\mathrm{T})$ data between 357 and $435 \mathrm{~K}$ for a coverage of less than one molecule per acid site, was found to be $12 \pm 1$ $\mathrm{kcal} / \mathrm{mol}$ [5]. The result presented here, in light of the necessary thermal corrections, is consistent with experiment.

Table 4

Energy Corrections to $\Delta E_{\text {desorp }}$ (in $\mathrm{kcal} / \mathrm{mol}$ ) from $8 \mathrm{~T}$ Atom Cluster

\begin{tabular}{ccc}
\hline$\Delta \mathrm{E}_{\text {desorp }}(\mathrm{HF} / 6-31 \mathrm{G}(\mathrm{d}))$ & 14.7 \\
& $\Delta(\mathrm{CS})$ & 2.0 \\
$\Delta(\mathrm{MP} 2)$ & 6.9 \\
$\Delta(\mathrm{QCI})$ & -0.9 \\
$\Delta(\mathrm{ZPE})$ & -2.9 \\
$\Delta(\mathrm{BS})$ & -5.5 \\
\hline \multicolumn{2}{c}{ desorp } & 14.3 \\
\hline
\end{tabular}

\section{CONCLUSIONS}

Using aluminosilicate cluster models of up to 100 atoms, we have carried out a computational study based on ab initio molecular orbital theory of adsorption of $\mathrm{H}_{2} \mathrm{O}$ at the acid site in the H-ZSM-5 zeolite. The computations incorporate local geometry optimization, large cluster size, and electron correlation in a unified way. The results indicate that the neutral $\mathrm{H}_{2} \mathrm{O}$ adsorption complex is more stable than the ion-pair structure previously proposed, which is probably a transition state. The calculated adsorption energy is roughly consistent with the published experimental value. Our results show the usefulness of such computations in investigations of reactions at the acid site in zeolites. It is also evident that the MP2 and the BLYP methods give correlation corrections for the desorption energy which are less than $1 \mathrm{kcal} / \mathrm{mol}$ from that of the more sophisticated QCISD(T) technique. Since the BLYP method can be implemented with a lower computational cost than MP2, it may be useful in future adsorption studies.

\section{ACKNOWLEDGMENTS}

This work was supported by the U. S. Department of Energy, Office of Basic Energy Sciences, Division of Materials Sciences, under Contract No. W-31-109ENG-38. We acknowledge a grant of computer time at the National Energy Research Supercomputer Center. Acknowledgment is also made to the Donors of 
the Petroleum Research Fund, adminstered by the American Chemical Society, for partial support of this research (S.A.Z.).

\section{REFERENCES}

1. H. V. Brand, L. A. Curtiss, and L. E. Iton, J. Phys. Chem. 97 (1993) 12773.

2. H. V. Brand, L. A. Curtiss, and L. E. Iton, J. Phys. Chem. 96 (1992) 7725.

3. E. H. Teunissen, A. P. Jansen, and R. A. van Santen, J. Phys. Chem. 99 (1995) 1873.

4. J. Sauer, P. Ugliengo, E. Garrone, and V. R. Saunders, Chem. Rev. 94 (1994) 2095.

5. A. Ison and R. J. Gorte, J. Catal. 89 (1984) 150.

6. M. T. Aronson, R. J. Gorte, and W. E. Farneth, J. Catal. 105 (1987) 455.

7. J. C. Sauer, C. Kolmel, F. Haase, and R. Ahlrichs, in Proceedings of the Ninth International Zeolite Conference (Montreal 1992), R. von Ballmoos et al., eds., Reed Publishing, Stoneham, MA, Vol. I (1993) 679.

8. A. G. Pelmenschikov and R. A. van Santen, J. Phys. Chem. 97 (1993) 10678.

9. F. Haase and J. Sauer, J. Phys. Chem. 98 (1994) 3083.

10. S. A. Zygmunt, H. V. Brand, D. J. Lucas, L. E. Iton, and L. A. Curtiss, J. Mol. Struct. (Theochem) 314 (1994) 113.

11. W. J. Hehre, L. Radom, J. A. Pople, and P. v. R. Schleyer, Ab Initio Molecular Orbital Theory. (John Wiley, New York) 1987.

12. Gaussian 92, M. J. Frisch et al. (Gaussian, Inc., Pittsburgh, PA 15106) 1992.

13. R. G. Parr and W. Yang, Density-Functional Theory of Atoms and Molecules (Oxford Univ. Press, New York) 1989.

14. H. van Koningsveld, H. Van Bekkum, J. C. Jansen, Acta Crystallogr. B43 (1987) 127.

15. L. A. Curtiss, K. Raghavachari, and J. A. Pople, J. Phys. Chem. 98 (1993) 1293.

16. P. M. W. Gill, B. G. Johnson, J. A. Pople, and M. J. Frisch, Chem. Phys. Lett. 197 (1992) 499.

17. J. A. Pople, M. Head-Gordon, and K. Raghavachari, J. Phys. Chem. 87 (1987) 5968.

18. J. Sauer, H. Horn, M. Haser, and R. Ahlrichs, Chem. Phys. Lett. 173 (1990) 26.

19. J. E. Del Bene, H. D. Mettee, M. J. Frisch, B. T. Luke, and J. A. Pople, J. Phys. Chem. 87 (1983) 3279.

20. E. Kassab, K. Seiti, and M. Allavena, J. Phys. Chem. 95 (1990) 9425. 
